\title{
Gender Differences in Self-Perceived Personal Resources of Older Adults with Generalized Anxiety Symptoms
}

Friederike H Boehlen ${ }^{1 *}$, Wolfgang Herzog ${ }^{1}$, Dieter Schellberg ${ }^{1}$, Imad Maatouk ${ }^{1}$, Kai-Uwe Saum ${ }^{2}$, Hermann Brenner ${ }^{2}$ and Beate Wild ${ }^{1}$

${ }^{1}$ Department of General Internal Medicine and Psychosomatics, Medical University Hospital, INF 410, 69120 Heidelberg, Germany

${ }^{2}$ Division of Clinical Epidemiology and Aging Research, German Cancer Research Center, INF 581, 69120 Heidelberg, Germany

"Corresponding author: Friederike H Boehlen, Department of General Internal Medicine and Psychosomatics, Medical University Hospital, INF 410,69120 Heidelberg, Germany, Tel: +49-(0)-6221-56-8649; Fax: +49-(0)-6221-56-5749; E-mail: friederike.boehlen@med.uni-heidelberg.de

Received date: April 07, 2017; Accepted date: April 26, 2017; Published date: April 28, 2017

Copyright: ( $) 2017$ Boehlen $\mathrm{FH}$, et al. This is an open-access article distributed under the terms of the Creative Commons Attribution License, which permits unrestricted use, distribution, and reproduction in any medium, provided the original author and source are credited.

\begin{abstract}
Background: Symptoms of general anxiety disorder (GAD) are common in older age, especially in women. Gender and sex differences in anxiety influence the way individuals interact with others and how they cope with new circumstances. Psychosocial resources (personal traits, social contacts, etc.) play an important role in the process of dealing with subjective worries and difficult situations. The aim of this study is to examine gender differences of selfperceived personal resources in elderly patients.
\end{abstract}

Methods: 3124 elderly persons (ages 55-85) were included in the study at the third follow-up of the large population-based German ESTHER study. GAD-symptoms were measured with the GAD-7 (cut-point>5). Psychosocial resources were assessed during a home visit by trained study doctors using a list of 26 different items.

Results: GAD-symptoms were found in 434 individuals (13.9\%; $67.1 \%$ female, $32.9 \%$ male). Self- efficacy, family, and feeling needed were the most frequently reported resources in older adults with GAD-symptoms. Personal resources (composure, humor) and social resources (partner, leisure activities) were reported significantly less frequently by elderly women compared to men. Women with GAD-symptoms showed a significantly reduced quality of life, a higher severity of somatic symptoms, and a higher degree of loneliness compared to men.

Keywords: Generalized anxiety; Disability; Mental disorders

\section{Introduction}

Anxiety in older age is common [1]. Prevalence rates of Generalized Anxiety Disorder (GAD) in older individuals range between $2.8 \%$ and $7.3 \%[2,3]$. GAD is characterized by uncontrollable worries over a period of at least 6 months [4]. In older persons it comprises a wide range of physical vegetative symptoms such as sleep disturbances and palpitations [5]. Furthermore, individuals with GAD often show symptoms of depression [6]. GAD is associated with disability and an impaired quality of life [7]. In addition, anxiety influences the way individuals interact with family and friends and how they face challenges, often resulting in difficulties in interpersonal relationships [8].

Generalized anxiety disorder is more frequently diagnosed in females $[9,10]$. Women with GAD show higher levels of anxiety and a higher degree of functional impairment $[3,11]$. Previous studies have indicated that women have higher rates of comorbid mood disorders, whereas men with GAD-symptoms were more frequently codiagnosed with substance use disorders or antisocial behaviour $[3,10]$. Biological factors such as hormonal influences and socio-cultural factors appear to contribute to gender differences in GAD.

Both physical and mental impairment, as well as socialization processes, shape the way a person perceives his or her personal strengths. Psychosocial resources play an important role in the process of coping with both physical and mental impairment as well as with the integration of new circumstances [12,13]. Resources can be personal resources (self-efficacy, optimism, composure) or social contacts (support through family, spouse, and/or health professionals). Environmental factors (financial security or work) can also be perceived as supportive elements. Current research shows that psychological and social resources correspond to physiological resilience [14], and that active participation is fundamental for the process of recovery [15].

A previous study indicated that older individuals with mental illness reported coping resources and social support significantly less frequently in comparison to non-mentally ill persons [16]. In individuals with GAD, reduced optimism and a heightened neural response to everyday worries was shown [17]. In older women selfefficacy was negatively correlated with age [18].

To date however, no study has investigated whether and how older men and women with GAD symptoms differ in their self-perceived psychosocial resources. This is the first study that is asking a large sample of older individuals with GAD-symptoms about factors in their lives that they perceive as strength-giving.

Better knowledge regarding the differences in psychosocial resources of older women and men with GAD-symptoms could provide important information for gender-specific treatment of anxiety in age. 


\section{Methods}

\section{Study sample}

The data were derived from the third follow-up of the ESTHER study (German: Epidemiologische Studie zu Chancen der Verhuetung, Frueherkennung und optimierten Therapie chronischer Erkrankungen in der aelteren Bevoelkerung). The ESTHER study is a populationbased cohort study conducted in Germany. Its aim is epidemiological research on prevention, early recognition, and optimal treatment of chronic diseases in an elderly population $[19,20]$. The study population ( $\mathrm{n}=9949$ at baseline) was initially recruited between July, 2000, and December, 2002, by general practitioners in Germany in the Federal State of Saarland in the course of a health check-up that is offered to adults (older than age 55). Baseline data showed that the ESTHER study sample was representative of the general German population with respect to both demographic variables and chronic diseases [20]. Follow-ups were conducted 2, 5, and 8 years after recruitment. At the beginning of the third (eight-year) follow-up of the ESTHER study,
8265 participants were eligible. All in all, between 2008 and 2010, a total of 6063 participants took part in this part of the study. 3124 of these ESTHER participants gave their consent for an additional home visit, conducted by trained study doctors. The home visit served as a comprehensive assessment regarding functional status as well as medical, pharmacological, socio-economic, and psychosocial aspects of their life. This part of the study was based on cross-sectional data of the 3124 ESTHER participants who attended the third follow-up and the additional home visit.

\section{Measurements}

\section{Personal resources}

During a standardized interview questions regarding personal resources were asked using the following question: "What gives you strength at this time of your life?" Multiple answers were allowed, using a list of 26 different categories (see Table 1) that comprised coping resources as well as social resources and structural aspects.

\begin{tabular}{|c|c|c|c|c|}
\hline Coping resources & $\begin{array}{l}\text { Social resources } \\
\text { (free-time) }\end{array}$ & $\begin{array}{l}\text { Social resources } \\
\text { (family) }\end{array}$ & External support & Independent items \\
\hline Mastery & Leisure activities & Partner & Profess. support & Financial resources \\
\hline Hope & Physical activity & Family & Social support & Work \\
\hline Optimism & Solo activities & Social activity & & Religiosity \\
\hline Health & Colleagues & & & Talking to someone \\
\hline Goals & Volunteer work & & & Social contact in general \\
\hline Self-efficacy & & & & \\
\hline Composure & & & & \\
\hline Humor & & & & \\
\hline New acquaintances & & & & \\
\hline Creativity & & & & \\
\hline Feeling needed & & & & \\
\hline
\end{tabular}

Table 1: List of response options for the question: "What gives you strength at this time of your life?"

\section{Generalized anxiety disorder symptoms}

Generalized anxiety disorder symptoms were measured by using the GAD-7 (seven-item Generalized Anxiety Disorder Scale) [21]. The seven items of the GAD represent the criteria of Generalized Anxiety Disorder of the Diagnostic and Statistical Manual of Mental Disorders, Fourth Edition (DSM-IV) [22]. The GAD-7 was validated in a large sample of primary care patients and showed good psychometric properties [23]. In a previous study, in the ESTHER study sample, it was shown that in elderly patients it would be advisable to lower the cut- off-point for detecting GAD from 10 to 5 [21]. Thus, in our study, participants with a GAD-7 $>5$ were categorized as having symptoms of a generalized anxiety disorder.

\section{Covariates}

Diagnosis of depression and somatization symptoms: Depression was measured using the 8 -item depression module of the Patient
Health Questionnaire (PHQ). The PHQ-8 consists of eight of the nine DSM-IV criteria on which the diagnosis of depressive disorders is based [24]. The ninth criterion asks for suicidal ideation and was omitted in the present investigation. The following two algorithms were used to define current depression: A minor (major) depressive disorder was assumed if: (1) 2-4 ( $\geq 5)$ of the 8 items were present on "more than half the days" and one item was depressed mood or anhedonia or (2), if participants had a PHQ-8 score $>10$. Somatization symptoms were measured by the adapted shortened version of the PHQ-15 comprised of 13 questions that included questions about physical pain [25]. Questions concerning problems during menstruation or sexual intercourse were omitted due to the agecomposition of the study sample. Persons with a somatic symptom score $\geq 13$ were categorized as having "somatization symptoms" in contrast to those with a score $<13$ [25].

Loneliness and Social Isolation: The degree of "loneliness" was measured by using a three-item questionnaire derived from the revised 
UCLA Loneliness Scale that has been validated for use in large surveys $[26,27]$. It is comprised of three items: "How often do you feel lonely?", "How often do you feel that you lack companionship?", and "How often do you feel left out?". The response categories were coded 1 (hardly ever), 2 (some of the time), and 3 (often). We calculated a total score, with the higher scores indicating greater loneliness. Participants with a score of seven and greater were defined as being "more lonely", which means that they responded to at least one of the mentioned questions with "often" and to the other questions with "sometimes".

To assess the perceived social support received by family and friends we used the Lubben Social Network Scale-6 (LSNS-6). This is a sixitem, self-reported scale to assess social isolation in older adults. The LSNS-6 measures the frequency and the quality of contacts of a participant's social network (including both family members and nonrelated persons). The score ranges from 0 -30 with a cut-off of less than 12 for defining individuals as being socially isolated [28]. Two subscale scores, ranging from 0 to 15 , measure the social network regarding family and friends.

Health-related Quality of Life (HRQOL): Health-related quality of life was measured with the Short-Form General Health Survey (SF-12) [29]. The SF-12 provides information on physical and mental quality of life and shows good psychometric criteria. Health-related Quality of Life is measured by a physical (PCS) and a mental (MCS) component score, each ranging from 0 to 100 -with higher scores indicating a higher quality of life.

\section{Statistical analysis}

Principal components analysis (PCA) was used to reduce the 26 items by screening for underlying factors [16]. Thus, items were categorized according to 1) coping resources, 2) social resources (freetime), 3) social resources (family), and external support. Five of 26 items could not be grouped and remained independent (religiosity, financial resources, work, social contacts in general, talking to someone) (see Table 1). Those independent items were evaluated separately.

For the group of elderly people with GAD-symptoms, percentages and confidence intervals were calculated for each of the 26 resource items. Female as well as male participants were compared using $\mathrm{Chi}^{2}$ test. For the evaluation of the four resource factors, for each participant each item of a factor was coded with 0 when he/she had not reported this item as a personal resource, and coded with 1 when he/she had reported it as a personal resource. Both mean sum scores and standard deviations were calculated. Wilcoxon Rank Sum Tests were used to compare the mean sum scores between subgroups. Gender differences in HRQOL, loneliness, and social isolation were evaluated by using $\mathrm{Chi}^{2}$-tests or t-tests.

Statistical analysis was performed using SAS, version 9.4.

\section{Results}

434 participants $(13.9 \%$; $95 \%$-confidence interval $=(12.7 ; 15.2))$ had a GAD-7 score greater than 5 and were defined as the group with symptoms of generalized anxiety disorder. All 434 participants with a GAD-score $>5$ answered the question regarding personal resources and were therefore included in the study.
$67.1 \%$ of the included participants with GAD-symptoms were female, $32.9 \%$ male. Female participants showed significantly higher GAD-scores in comparison to men (8.3 (SD: 3.5) vs. 7.6 (SD: 2.9); $\mathrm{p}=$. 022). The mean age of the study sample was 68.9 years of age (SD: 6.4). Table 2 shows the demographic characteristics of the study.

\begin{tabular}{|c|c|c|}
\hline Baseline variables & $\mathbf{N}$ & (\%) \\
\hline \multicolumn{3}{|l|}{ Sex } \\
\hline Female & 291 & 67.1 \\
\hline Male & 143 & 32.9 \\
\hline \multicolumn{3}{|l|}{ Age } \\
\hline $55-64$ & 135 & 31.3 \\
\hline $65-74$ & 203 & 46.8 \\
\hline $75-84$ & 95 & 21.9 \\
\hline \multicolumn{3}{|l|}{ Education (years) } \\
\hline $0-8$ & 7 & 1.7 \\
\hline 09-Oct & 364 & 85.7 \\
\hline $11-12$ & 35 & 8.2 \\
\hline$>12$ & 19 & 4.5 \\
\hline \multicolumn{3}{|l|}{ Marital status } \\
\hline Single & 15 & 3.5 \\
\hline Married & 275 & 64.7 \\
\hline Divorced/widowed & 135 & 31.8 \\
\hline
\end{tabular}

Table 2: Demographic characteristics of the study sample $(n=434)$.

A high degree of loneliness was reported by $37.7 \%(33.1 ; 42.5)$ of all patients with GAD-symptoms; social isolation measured by the LSNS- 6 was reported by $22.1 \%(18.3 ; 26.3)$ of older adults with GADsymptoms. A GAD-7 score greater than 10 was found in 104 participants (3.3\%: $75 \%$ female, $25 \%$ male).

\section{Personal Resources}

Total sample of GAD-patients: In the total group of older individuals with GAD-symptoms, family $(80.4 \%$, 95\% -CI=(76.4; $84.1))$, self-efficacy $(69.4 \% ; 95 \%-\mathrm{CI}=(64.8 ; 73.7))$, and feeling needed $(65.4 \%, 95 \%-\mathrm{CI}=(60.8 ; 69.9))$ were the most frequently reported resources. Persons with GAD-symptoms reported family and selfefficacy significantly less frequently as a resource in comparison with persons without GAD-symptoms $(\mathrm{p}<.001 ; \mathrm{p}<.001)$, but reported no significant difference in the perception of "feeling needed" as a resource $(p=.067)$ (see Figure 1). There was no significant difference between female and male participants regarding the frequency of reporting these resources. 


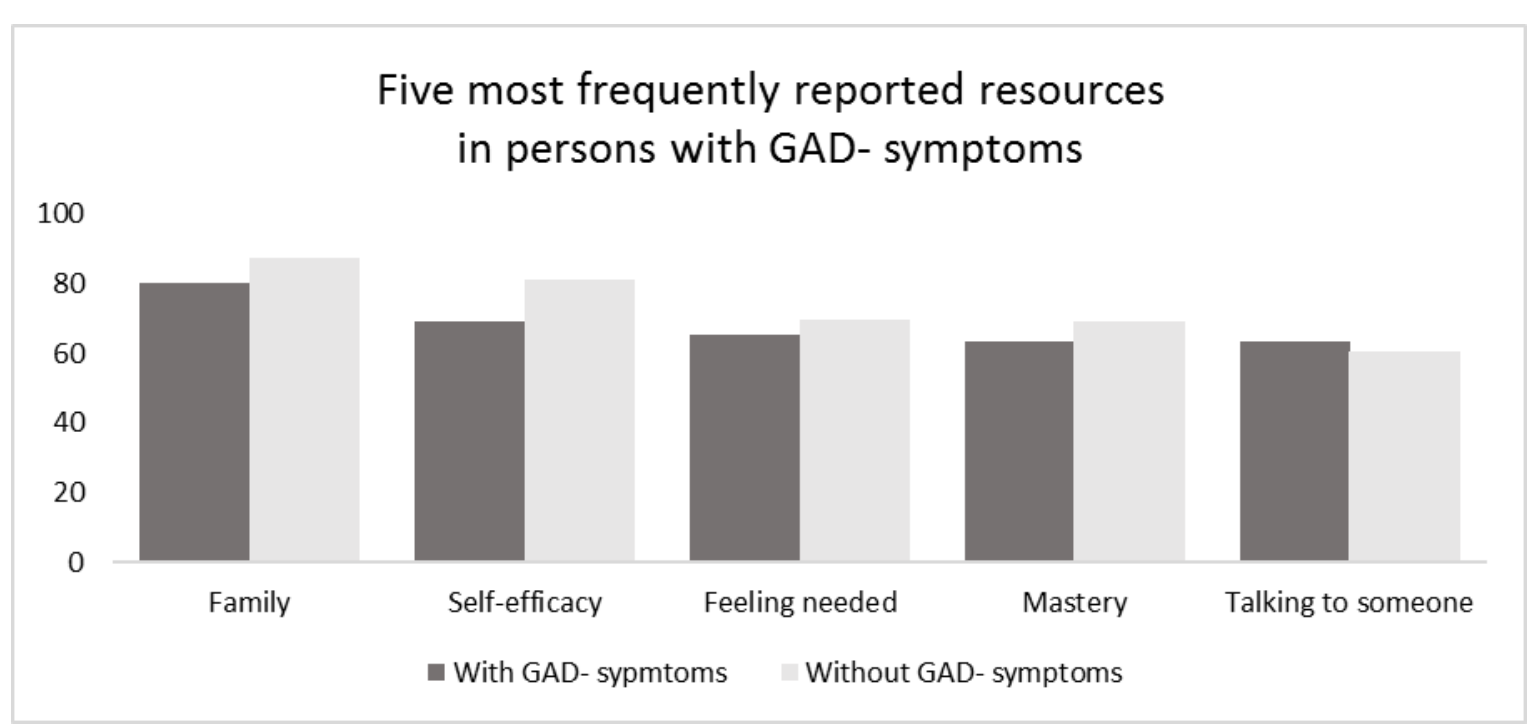

Figure 1: Five most frequently reported resources in persons with GAD-symptoms in comparison with persons without GAD-symptoms.

Gender differences: Female participants with GAD-symptoms reported religiosity significantly more frequently as a resource compared with male participants $(\mathrm{p}=.001$; see Table 3 ). Male GADpatients regarded coping resources such as composure $(\mathrm{p}=.001)$ and humor $(\mathrm{p}=.036)$ significantly more frequently as a resource compared to women, as well as health $(\mathrm{p}=.025)$, leisure activities $(\mathrm{p}<.001)$, and physical activity $(\mathrm{p}=.042) .77 .6 \%$ of all male participants with GADsymptoms perceived their partner as a resource, whereas only $49.5 \%$ of the female participants did so $(\mathrm{p}<.001)$. Men were significantly more frequently married in comparison to women $(81.6 \%$ vs. $56.3 \%$; $\mathrm{p}<$. 001 ), but even in married individuals men reported their partner significantly more frequently as a resource in comparison to women ( $85.2 \%$ vs. $72.5 \% ; \mathrm{p}=.012$ ). Table 3 gives an overview of the gender differences of resources in elder people with generalized GADsymptoms.

\begin{tabular}{|c|c|c|c|c|}
\hline & Female & Male & & \\
\hline Resources & $(\%, 95 \%-\mathrm{Cl})$ & $(\%, 95 \%-\mathrm{Cl})$ & $x^{2}(1)$ & $p$ value \\
\hline Religiosity & $56.7(50.8 ; 62.5)$ & $39.9(31.8 ; 48.4)$ & 10.88 & 0.001 \\
\hline Composure & $29.9(24.7 ; 35.5)$ & $45.5(37.1 ; 54.0)$ & 10.2 & 0.001 \\
\hline Humor & $50.9(45.0 ; 56.7)$ & $61.5(53.0 ; 69.6)$ & 4.41 & 0.036 \\
\hline Health & $51.6(45.6 ; 57.4)$ & $62.9(54.5 ; 70.9)$ & 5.03 & 0.025 \\
\hline Partnera & $49.5(43.6 ; 55.4)$ & $77.6(69.9 ; 84.2)$ & 31.33 & $<.001$ \\
\hline Leisure activities & $47.1(41.3 ; 53.0)$ & $66.4(58.1 ; 74.1)$ & 14.44 & $<.001$ \\
\hline Physical activity & $34.0(28.6 ; 39.8)$ & $44.1(35.8 ; 52.6)$ & 4.13 & 0.042 \\
\hline
\end{tabular}

Table 3: Significant gender differences of resources in older adults with generalized anxiety disorder symptoms.

The Wilcoxon rank-sum test showed that male GAD-patients reported coping resources and social resources (either free-time or family) significantly more frequently in comparison to females (coping resources: $\mathrm{Z}=2.340 ; \mathrm{p}=.019$; social resources (free-time): $\mathrm{Z}=3.143 ; \mathrm{p}=$. 001; social resources (family): $Z=3.962 ; p<.001$ ) (see Table 4). There was no significant difference in reporting external resources in women or men $(\mathrm{Z}=0.359 \mathrm{p}=.072)$. Table 4 shows the mean sum scores of resource dimensions in male and female participants with GADsymptoms.

\begin{tabular}{|l|l|l|l|l|}
\hline & Female & Male & \\
\cline { 2 - 3 } & $\begin{array}{l}\text { (Mean score; } \\
\text { SD) }\end{array}$ & $\begin{array}{l}\text { (Mean scores; } \\
\text { SD) }\end{array}$ & Test & p value \\
\hline $\begin{array}{l}\text { Coping } \\
\text { resources }\end{array}$ & $5.3 \pm 3.1$ & $6.0 \pm 2.9$ & $Z=2.340$ & 0.019 \\
\hline $\begin{array}{l}\text { Social } \\
\text { resources free- } \\
\text { time }\end{array}$ & $1.9 \pm 1.4$ & $2.3 \pm 1.4$ & $Z$ & \\
\hline $\begin{array}{l}\text { Social } \\
\text { resources } \\
\text { family }\end{array}$ & $1.9 \pm 1.0$ & $2.2 \pm 1.0$ & $\mathrm{Z}=3.962$ & 0.001 \\
\hline $\begin{array}{l}\text { External } \\
\text { resources }\end{array}$ & $0.6 \pm 0.7$ & $0.6 \pm 0.8$ & $\mathrm{Z}=0.359$ & 0.072 \\
\hline Resources total & $12.4 \pm 5.7$ & $13.9 \pm 5.4$ & $\mathrm{Z}=2.527$ & 0.012 \\
\hline
\end{tabular}

Table 4: Comparison of resources groups of female and male participants with generalized anxiety disorder symptoms.

There was no significant gender difference regarding depression diagnosis according to the PHQ-8 in older women and men with GAD-symptoms ( $36.8 \%$ vs. $33.1 \%$; $\mathrm{p}=.450)$, but there was a higher prevalence of somatization symptoms in women in comparison with men $(29.9 \%$ vs. $16.1 \% ; \mathrm{p}=.002)$. Female individuals perceived themselves significantly more frequently as being lonely $(42.4 \% \mathrm{vs}$. $28.7 \% ; \mathrm{p}=.004)$ in comparison to males. There was no significant difference in the mean scores of the LSNS-6 in men and women, indicating that there was no significant difference in the social network 
of older men and women. $21.7 \%$ of older men and $22.3 \%$ of women showed signs of social isolation ( $\mathrm{p}=.877$ ). Male individuals with GADsymptoms showed a significantly higher MCS (mental component score of the SF-12 measuring HRQOL) in comparison to females, but no significant difference in the PCS (physical component score) (Table $5)$.

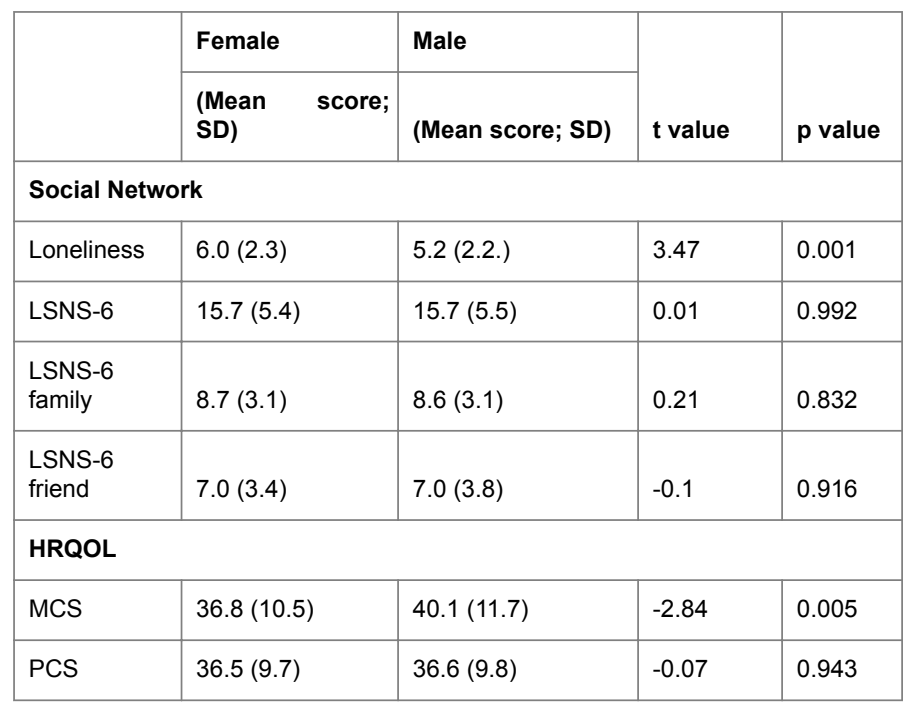

Table 5: Gender differences in social network and HRQOL in older adults with generalized anxiety disorder symptoms.

\section{Discussion}

This is the first study that has investigated gender differences in a wide range of psychosocial resources and other supportive elements in a large population-based sample of older persons with symptoms of generalized anxiety disorder.

In our study, twice as many female individuals were found who experienced symptoms of GAD in comparison to males. Women more frequently showed a high severity of somatization symptoms, which is in line with previous studies $[3,30]$. Our research differed from current research in that we did not find gender differences regarding depression diagnosis in our study sample [10].

Results show that family, self-efficacy, and feeling needed were the most frequently reported resources in older adults with generalized anxiety symptoms. While participants with GAD-symptoms reported family and self-efficacy significantly less frequently in comparison to individuals without GAD-symptoms, there were no differences regarding gender in reporting these resources. In married couples the partner was significantly less frequently reported as a resource by older women with GAD-symptoms in comparison to men. This corresponds with results of the total sample of the ESTHER- study [16]

In general, it is not surprising that older persons with GADsymptoms would report resources such as self-efficacy or mastery less frequently compared to individuals without GAD. However, our findings regarding other resources-for example the perception of family or spouse as a resource-are quite remarkable. It should therefore be explored further if persons with GAD-symptoms do perceive their family as less supportive or if they do, in fact, have fewer supportive family ties. Whisman et al., for instance, showed strong associations for marital discord for persons with GAD that could not be explained by general social dissatisfaction [8].
Furthermore, it is interesting that women with GAD-symptoms perceive their partner significantly less frequently as a resource in comparison to men. One reason could be that older women often take the caregiving position in relationships, particularly if the partner is avoidant towards social contacts and everyday activities. This corresponds with previous research that shows that wives with husbands in poor health frequently report high levels of marital conflict, but not vice versa [31]. However, in our study, explanations for this association remain speculative. Further evaluation is needed to clarify the background for this unequal pattern.

Our study indicates that in comparison to men, older women with GAD-symptoms experience loneliness more frequently. This is consistent with recent research [32]. Our study adds the interesting aspect that the social network of older men and women shows no significant difference. This raises the question if older women with GAD-symptoms perceive their social contacts as being less supportive and which aspects of their life induce the feeling of loneliness.

In contrast to women, older men with GAD-symptoms reported coping resources (composure and humor), social resources, and freetime activities (leisure activities and physical activity) significantly more frequently as a personal resource. One reason could be that older men report their strengths more frequently or that they perceive their strengths more intensely. McLean et al., [33] showed that identification with a masculine gender role may result in under-reporting symptoms of anxiety. In this context, it was supposed that men are more encouraged to display strength and to confront fears throughout their socialization, whereas in women avoidance is more accepted [33]. Women, both with and without symptoms of severe anxiety, were shown to reflect about themselves more critically displaying a tendency to ruminate more and higher levels of depression in comparison to men [34]. Other reasons could be derived from differences in the social network of women and men as well as their socialization. In this context, Stokes et al. described that older women tend to develop more "close dyadic ties" that are less related to large social networks in comparison to men [35]. Furthermore, Klose et al. showed that belonging to a higher class, working full time, and having children appeared to be supportive factors for mental illness in men only [36]. Regarding this, it can be assumed that older men have acquired a more divergent network of external contacts throughout their life and perceive external factors such as work or family more frequently as strength-giving and therefore disease preventing.

Finally, it has to be considered that older women with GAD show an increased severity of anxiety symptoms and physical impairment, that could also have an effect on the perception of personal resources [3].

Our study has two limitations: Firstly, we could only determine associations and not temporal or causal relationships; secondly, we did not use detailed questionnaires to assess the degree of specific coping resources, but rather offered a catalog of possible answers comprised of elements about the various areas. However, we decided to examine personal resources using this more generalized approach because it provided direct information on the factors that were perceived as strength-giving by older persons with GAD-symptoms. Thus, our study gives a broad overview, but misses going into detail concerning the individual items. This should be considered when interpreting our data.

Additionally, if we were to reflect on the specificity of the GADconcept in relation to psychosocial resources, we would hypothesize that the change in resources in the elderly with GAD-symptoms is 
similar to the change in resources in older people with other impairments. In our previous study [16], we found that older people with frailty, complexity, or mental illness reported less personal and social resources and more external resources. Our results indicate that there could be a general association between these measurementconstructs and a perception of reduced personal resources. It could therefore be, that all the constructs that measure aspects of negative well-being are broadly in the same way related to self-perceived resources. This would lead to the question if it would be advisable to offer support for older people with a perception of reduced personal resources.

The particular strengths of this study are the sample size of the study population ( $\mathrm{n}=3124 ; 434$ participants with GAD-symptoms) and the method of recording data on resources by trained study doctors. This strengthens the quality of the medical data and provides us with the exceptional possibility to connect health-care information and social variables in an elderly population. Furthermore, our study promotes a focus on the strengths of older adults with generalized anxiety symptoms and therefore does not concur with the feelings of weakness and helplessness that are often experienced by older anxious persons. Our findings could be useful for further research for investigating associations of psychosocial resources in women and men with other outcomes, such as multimorbidity or health care use.

In summary, our study shows that gender differences of generalized anxiety disorder exist not only in terms of prevalence and symptom severity, but also in the manner in which a person assesses the strength-giving factors of his or her life. Our study underlines that older women with GAD-symptoms show significantly lower levels in the perception of personal resources, a lower quality of life, and a higher level of loneliness in comparison to men. When offering psychotherapy to persons experiencing generalized anxiety disorder, these factors should be taken into account.

\section{Acknowledgement}

This study was part of the consortium "Multimorbidity and frailty at old age: epidemiology, biology, psychiatric comorbidity, medical care, and costs". It was funded by the German Ministry of Research and Education (grant number 01ET0718). The study (including follow-up examinations) was approved by the Ethics Committee of the Medical Faculty, University of Heidelberg and the Medical Association of Saarland. The authors thank all participants for making this study possible. We acknowledge financial support by Deutsche Forschungsgemeinschaft and Ruprecht-Karls-Universität Heidelberg within the funding programme Open Access Publishing.

\section{References}

1. Mackenzie CS, Reynolds K, Chou KL, Pagura J, Sareen J (2011) Prevalence and correlates of generalized anxiety disorder in a national sample of older adults. Am J Geriatr Psychiatry 19: 305-315.

2. Bryant C, Jackson H, Ames D (2008) The prevalence of anxiety in older adults: methodological issues and a review of the literature. J Affect Disord 109: 233-250.

3. Vesga-López O, Schneier FR, Wang S, Heimberg RG, Liu SM, et al., (2008) Gender differences in generalized anxiety disorder: results from the National Epidemiologic Survey on Alcohol and Related Conditions (NESARC). J Clin Psychiatry 69: 1606-1616.

4. http://dsm.psychiatryonline.org/doi/book/10.1176/appi.books. 9780890425596
5. Miloyan B, Pachana NA (2015) Clinical significance of worry and physical symptoms in late-life generalized anxiety disorder. International journal of geriatric psychiatry 30: 1186-1194.

6. Schoevers RA, Deeg DJ, van Tilburg W, Beekman AT (2005) Depression and generalized anxiety disorder: co-occurrence and longitudinal patterns in elderly patients. Am J Geriatr Psychiatry 13: 31-39.

7. Porensky EK, Dew MA, Karp JF, Skidmore E, Rollman BL, et al., The burden of late-life generalized anxiety disorder: effects on disability, health-related quality of life, and healthcare utilization. Am J Geriatr Psychiatry 17: 473-482.

8. Whisman MA, Sheldon CT, Goering P (2000) Psychiatric disorders and dissatisfaction with social relationships: does type of relationship matter? J Abnorm Psychol 109: 803-808.

9. Gum AM, King-Kallimanis B, Kohn R (2009) Prevalence of mood, anxiety, and substance-abuse disorders for older Americans in the national comorbidity survey-replication. Am J Geriatr Psychiatry 17: 769-781.

10. McLean CP, Asnaani A, Litz BT, Hofmann SG (2011) Gender differences in anxiety disorders: prevalence, course of illness, comorbidity and burden of illness. J Psychiatr Res 45: 1027-1035.

11. Bekker MH, van Mens-Verhulst J (2007) Anxiety disorders: sex differences in prevalence, degree, and background, but gender-neutral treatment. Gend Med 4: S178-S193.

12. Taylor SE, Stanton AL (2007) Coping resources, coping processes, and mental health. Annu Rev Clin Psychol 3: 377-401.

13. http://www.springerpub.com/stress-appraisal-and-coping.html

14. Meeks S, Van Haitsma K, Mast BT, Arnold S, Streim JE, et al. (2016) Psychological and social resources relate to biomarkers of allostasis in newly admitted nursing home residents. Aging \& mental health 20: 88-99.

15. Steunenberg B, Beekman AT, Deeg DJ, Bremmer MA, Kerkhof AJ (2007) Mastery and neuroticism predict recovery of depression in later life. Am J Geriatr Psychiatry 15: 234-242.

16. Boehlen FH, Herzog W, Schellberg D, Maatouk I, Saum KU, et al. (2016) Self-perceived coping resources of middle-aged and older adults-results of a large population-based study. Aging Ment Health 1-7.

17. Blair KS, Otero M, Teng C, Geraci M, Ernst M, et al. (2017) Reduced optimism and a heightened neural response to everyday worries are specific to generalized anxiety disorder, and not seen in social anxiety. Psychol Med 14: 1-10.

18. Cybulski M, Cybulski L, Krajewska-Kulak E, Cwalina U (207) The level of emotion control, anxiety, and self-efficacy in the elderly in Bialystok, Poland. Clin Interv Aging 12: 305-314.

19. Gao L, Weck MN, Raum E, Stegmaier C, Rothenbacher D, et al. (2010) Sibship size, Helicobacter pylori infection and chronic atrophic gastritis: a population-based study among 9444 older adults from Germany. Int J Epidemiol 39: 129-134.

20. Löw M, Stegmaier C, Ziegler H, Rothenbacher D, Brenner H, et al. (2004) Epidemiological investigations of the chances of preventing, recognizing early and optimally treating chronic diseases in an elderly population (ESTHER study). Dtsch Med Wochenschr 129: 2643-2647.

21. Wild B, Eckl A, Herzog W, Niehoff D, Lechner S, et al. (2014) Assessing generalized anxiety disorder in elderly people using the GAD-7 and GAD-2 scales: results of a validation study. Am J Geriatr Psychiatry 22: 1029-1038.

22. http://pubman.mpdl.mpg.de/pubman/faces/ viewItemFullPage.jsp;jsessionid=ABB07A18B71F773676EB98230096B86 B?itemId=escidoc\%3A1629321\%3A1\&view=EXPORT

23. Spitzer RL, Kroenke K, Williams JB, Löwe B (2006) A brief measure for assessing generalized anxiety disorder: the GAD-7. Arch Intern Med 166: 1092-1097.

24. Kroenke K, Strine TW, Spitzer RL, Williams JB, Berry JT, et al. (2009) The PHQ-8 as a measure of current depression in the general population. J Affect Disord 114: 163-173. 
Citation: Boehlen FH, Herzog W, Schellberg D, Maatouk I, Saum KU, et al. (2017) Gender Differences in Self-Perceived Personal Resources of Older Adults with Generalized Anxiety Symptoms. J Aging Sci 5: 178. doi:10.4172/2329-8847.1000178

Page 7 of 7

25. Kroenke K, Spitzer RL, Williams JB (2002) The PHQ-15: validity of a new measure for evaluating the severity of somatic symptoms. Psychosom Med 64: 258-266.

26. Hughes ME (2004) A short scale for measuring loneliness in large surveys results from two population-based studies. Res Aging 26: 655-672.

27. Russell D, Peplau LA, Cutrona CE (1980) The revised UCLA Loneliness Scale: Concurrent and discriminant validity evidence. J Pers Soc Psychol 39: 472-480.

28. Lubben J, Blozik E, Gillmann G, Iliffe S, von Renteln Kruse W, et al. (2006) Performance of an abbreviated version of the Lubben Socia Network Scale among three European community-dwelling older adult populations. The Gerontologist 46: 503-513.

29. Bullinger M, Kirchberger I (1998) SF-36: Fragebogen zum Gesundheitszustand; Handanweisung. Hogrefe, Verlag für Psychologie 9003482

30. Ruscio AM, Hallion LS, Lim CC, Aguilar-Gaxiola S, Al-Hamzawi A, et al. (2017) Cross-sectional comparison of the epidemiology of dsm-5 generalized anxiety disorder across the globe. JAMA Psychiatry.
31. Iveniuk J, Waite LJ, McClintock MK, Teidt AD (2014) Marital Conflict in Older Couples: Positivity, Personality, and Health. J Marriage Fam 76: 130-144.

32. Cohen-Mansfield J, Hazan H, Lerman Y, Shalom V (2016) Correlates and predictors of loneliness in older-adults: a review of quantitative results informed by qualitative insights. Int Psychogeriatr 28: 557-576.

33. McLean CP, Anderson ER (2009) Brave men and timid women? A review of the gender differences in fear and anxiety. Clin Psychol Rev 29: 496-505.

34. Johnson DP, Whisman MA (2013) Gender differences in rumination: A meta-analysis. Personality and individual differences 55: 367-374.

35. Stokes J, Levin I (1986) Gender differences in predicting loneliness from social network characteristics. J Pers Soc Psychol 51: 1069.

36. Klose M, Jacobi F (2004) Can gender differences in the prevalence of mental disorders be explained by sociodemographic factors? Arch Womens Ment Health 7: 133-148. 